\title{
3D-nanoarchitectured $\mathrm{Pd} / \mathrm{Ni}$ catalysts prepared by atomic layer deposition for the electrooxidation of formic acid
}

\author{
Loïc Assaud ${ }^{1}$, Evans Monyoncho ${ }^{2}$, Kristina Pitzschel ${ }^{1}$, Anis Allagui ${ }^{2}$, \\ Matthieu Petit ${ }^{1}$, Margrit Hanbücken ${ }^{1}$, Elena A. Baranova ${ }^{*}{ }^{2}$ \\ and Lionel Santinacci ${ }^{*}$
}

\section{Full Research Paper}

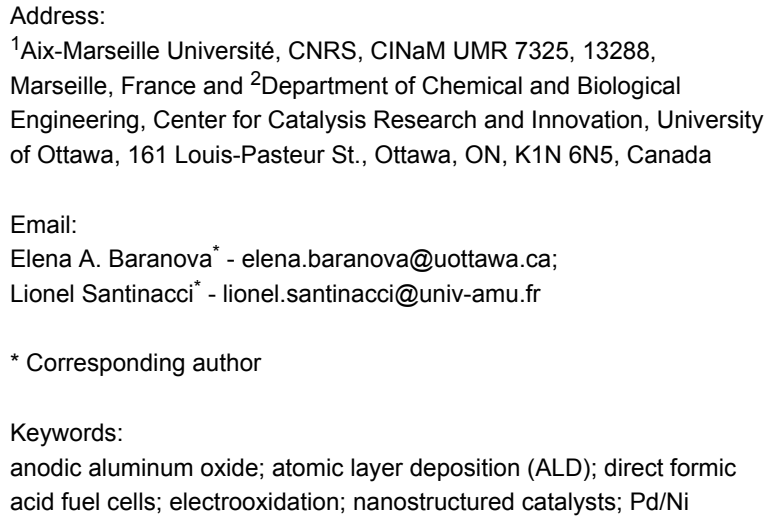

${ }^{1}$ Aix-Marseille Université, CNRS, CINaM UMR 7325, 13288, Marseille, France and ${ }^{2}$ Department of Chemical and Biological Engineering, Center for Catalysis Research and Innovation, University of Ottawa, 161 Louis-Pasteur St., Ottawa, ON, K1N 6N5, Canada

Email:

Elena A. Baranova* - elena.baranova@uottawa.ca;

Lionel Santinacci* - lionel.santinacci@univ-amu.fr

* Corresponding author

Keywords:

anodic aluminum oxide; atomic layer deposition (ALD); direct formic acid fuel cells; electrooxidation; nanostructured catalysts; $\mathrm{Pd} / \mathrm{Ni}$

\author{
doi:10.3762/bjnano.5.16 \\ Received: 30 September 2013 \\ Accepted: 14 January 2014 \\ Published: 12 February 2014
}

Beilstein J. Nanotechnol. 2014, 5, 162-172.

This article is part of the Thematic Series "Energy conversion applications of atomic layer deposition".

Guest Editor: J. Bachmann

(C) 2014 Assaud et al; licensee Beilstein-Institut.

License and terms: see end of document.

\begin{abstract}
Three-dimensionally (3D) nanoarchitectured palladium/nickel ( $\mathrm{Pd} / \mathrm{Ni}$ ) catalysts, which were prepared by atomic layer deposition (ALD) on high-aspect-ratio nanoporous alumina templates are investigated with regard to the electrooxidation of formic acid in an acidic medium ( $\left.0.5 \mathrm{M} \mathrm{H}_{2} \mathrm{SO}_{4}\right)$. Both deposition processes, $\mathrm{Ni}$ and $\mathrm{Pd}$, with various mass content ratios have been continuously monitored by using a quartz crystal microbalance. The morphology of the $\mathrm{Pd} / \mathrm{Ni}$ systems has been studied by electron microscopy and shows a homogeneous deposition of granularly structured Pd onto the Ni substrate. X-ray diffraction analysis performed on Ni and $\mathrm{NiO}$ substrates revealed an amorphous structure, while the Pd coating crystallized into a fcc lattice with a preferential orientation along the [220]-direction. Surface chemistry analysis by X-ray photoelectron spectroscopy showed both metallic and oxide contributions for the $\mathrm{Ni}$ and $\mathrm{Pd}$ deposits. Cyclic voltammetry of the $\mathrm{Pd} / \mathrm{Ni}$ nanocatalysts revealed that the electrooxidation of $\mathrm{HCOOH}$ proceeds through the direct dehydrogenation mechanism with the formation of active intermediates. High catalytic activities are measured for low masses of Pd coatings that were generated by a low number of ALD cycles, probably because of the cluster size effect, electronic interactions between $\mathrm{Pd}$ and $\mathrm{Ni}$, or diffusion effects.
\end{abstract}




\section{Introduction}

Over the last decade, the miniaturization of fuel cells for the fast expanding market of portable devices has become a challenging research topic. Direct formic acid fuel cell (DFAFC) systems as electrochemical power sources have many advantages such as the low-toxicity, unlike methanol, the low cost, and the low fuel crossover at a high power density [1-3]. Palladium is a good candidate to catalyze the electrooxidation of formic acid thanks to its good stability at low $\mathrm{pH}$ and its high activity [4-8]. The electrooxidation of $\mathrm{HCOOH}$ on $\mathrm{Pd}$ results in the formation of $\mathrm{CO}_{2}$ and protons [7], which is a direct dehydrogenation pathway through the formation of active intermediates without the generation of poisonous $\mathrm{CO}$ species (Scheme 1).

$$
\stackrel{\mathrm{HO}}{=} \stackrel{[\mathrm{Pd}]}{\longrightarrow} \mathrm{CO}_{2}+2 \mathrm{H}^{+}+2 \mathrm{e}^{-}
$$

Scheme 1: Pd-catalyzed electrooxidation of $\mathrm{HCOOH}$ on Pd surfaces.

Despite the advantages of Pd catalysts for the electrooxidation of formic acid, the activity is still not satisfactory enough for commercial applications and more importantly, $\mathrm{Pd}$ tends to dissolve and deactivate quickly by the impurities present in the electrolyte [9]. Additionally, reducing the noble metal loading by alloying Pd with a second cheap transition metal is essential for a viable development of DFAFCs. In recent studies, several metals such as $\mathrm{Cu}, \mathrm{Ni}, \mathrm{Fe}$ or Pt alloyed with Pd have been tested [10-13] for the electrooxidation reaction of $\mathrm{HCOOH}$, and have shown a significant increase of the catalytic activity when compared to pure Pd. Amongst them, the Pd/Ni bimetallic system has shown very promising results due to the favorable electronic effects that $\mathrm{Ni}$ brings into the system.

It is also well-known that decreasing the size of the active particles and thus increasing the electro-active surface area of the catalyst are interesting ways to improve the electrooxidation of $\mathrm{HCOOH}$. Nanostructured substrates such as nanowires, nanorods, nanopores or nanotubes have thus been investigated to enhance the catalytic efficiency and to reduce the costs [14]. On the other hand, the physical, chemical and electrochemical properties of the nanostructures are highly correlated with the technique of fabrication. Among the numerous methods that have been recently explored, the use of atomic layer deposition (ALD) to fabricate and/or functionalize nanostructures appears to be very promising. Catalysts grown by ALD often demonstrated similar or enhanced properties as compared to those grown by conventional methods, such as impregnation, ionexchange, and deposition-precipitation $[15,16]$. ALD has initially been used to produce oxide layers to support the cata- lysts [17], but two additional approaches have been recently proposed: ALD is either used to grow metallic clusters or it is applied to protect those metallic clusters with an ultrathin metal oxide layer (see, e.g., the reviews [18-20]). This deposition method is particularly interesting for electrocatalysis because it allows an accurate control of both growth rate and composition of the catalyst, and it provides a high coverage of high aspect ratio nanostructures [21-23]. It is therefore possible to precisely design catalysts onto nanoarchitectured supports that exhibit enhanced abilities for fuel cell applications [24,25].

As previously proposed [26], nanoporous anodic aluminum oxide (AAO) has been used as nanostructured support for the Pd catalysts. The AAO membranes are attractive because they exhibit a high specific surface area and the pore diameter and length can be tailored easily [27,28]. In this study, the usual two-step anodization process shown in Figure 1a-e, has been used to grow well-ordered porous structures. $\mathrm{Ni}$ and $\mathrm{Pd}$ are then successively deposited into the templates by ALD. The alumina membranes are firstly coated by $\mathrm{NiO}$ that is reduced to metallic $\mathrm{Ni}$ by annealing under $\mathrm{H}_{2}$ atmosphere [29,30] (Figure 1f). The Pd clusters are then deposited directly onto the Ni films (Figure 1g). Both $\mathrm{NiO}$ and $\mathrm{Pd}$ deposition processes have been monitored by quartz crystal microbalance (QCM). The morphology, the chemical composition and the crystalline structures have been investigated by scanning and transmission electron microscopy (SEM and TEM) and atomic force microscopy (AFM), X-ray photoelectron spectroscopy (XPS) and X-ray diffraction (XRD), respectively. The electrocatalytic activity of the $\mathrm{Pd} / \mathrm{Ni}$ systems, which were deposited on three-dimensional alumina membranes with various mass content ratios, for the electrooxidation of formic acid in acidic solution has been studied by cyclic voltammetry (CV).

\section{Results and Discussion Nickel deposition}

Since ALD processes have been developed mainly for metal oxide and nitride thin films, metal depositions have been hampered mostly by the lack of relevant and stable precursors [31]. Although a new class of precursors that facilitates the direct metal deposition, has recently been proposed [32], several metals are often grown through a two-step process: (i) deposition of the metallic oxide and (ii) subsequent reduction (see, e.g., [29,30]). Metallic Ni is therefore grown by using such an approach [33,34]: the deposition of $\mathrm{NiO}$ is carried out from nickelocene $\left(\mathrm{NiCp}_{2}\right)$ and $\mathrm{O}_{3}$ precursors and the reduction of this oxide film to metallic $\mathrm{Ni}$ is obtained by a reductive annealing process under $\mathrm{H}_{2}$ atmosphere. The relative mass, $m$, gain and loss have been monitored during the process by QCM and are plotted in Figure 2a. A regular cyclic variation of the mass vs 


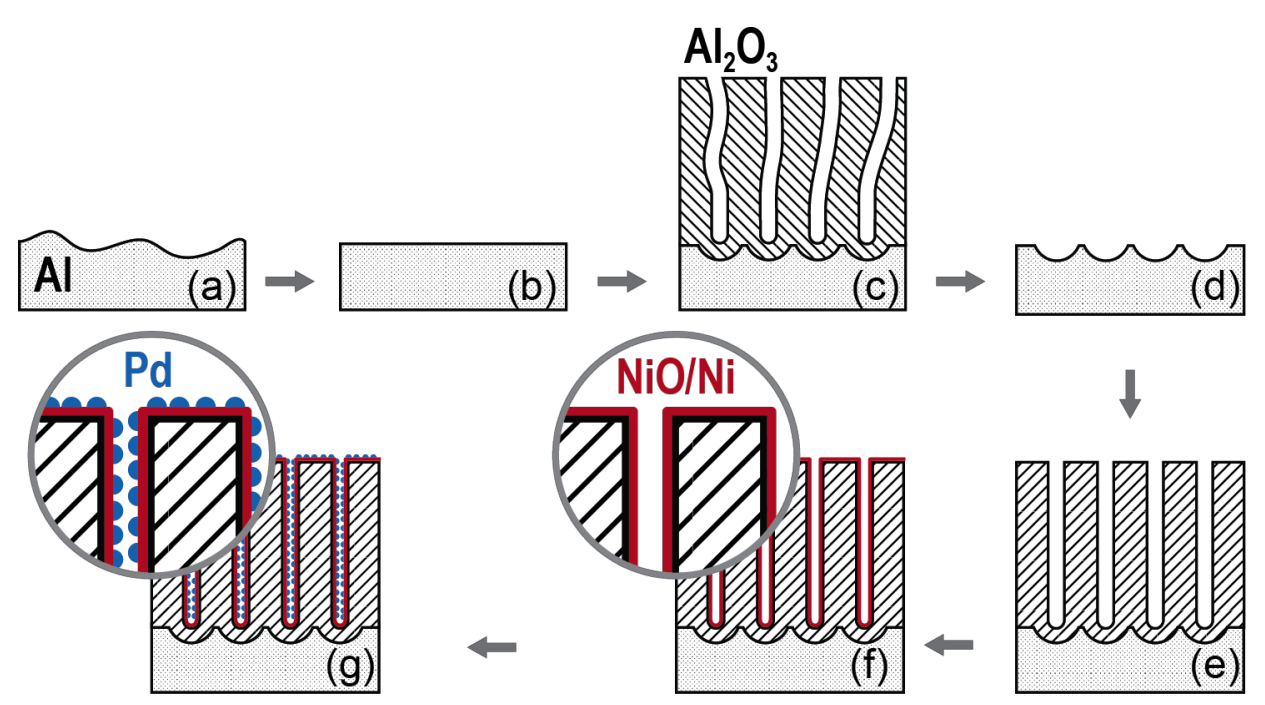

Figure 1: Schematic description of the anodic alumina template fabrication and successive functionalization. (a) Initial Al disc, (b) electropolished Al disc, (c) anodic $\mathrm{Al}_{2} \mathrm{O}_{3}$ porous layer, (d) pre-ordered $\mathrm{Al}$ disc after removal of the AAO sacrificial layer, (e) self-ordered AAO membrane, (f) Ni/NiO film deposited by ALD and reduced by annealing post treatment, $(\mathrm{g})$ Pd cluster layer grown by ALD.

the number of ALD cycles is observed with an overall linear evolution, which is typical for an ALD process with constant growth rate. An enlarged view of one cycle presented in Figure $2 \mathrm{~b}$ shows in detail the process during the four successive steps of the NiO ALD sequence. The QCM measurements indicate that the exposure and purging duration are optimized for both $\mathrm{NiCp}_{2}$ and $\mathrm{O}_{3}$ pulses. The mass variations are indeed reaching a plateau at the end of the exposure and purging stages. After the short $\mathrm{NiCp}_{2}$ pulse (green period on the far left of Figure $2 b$ ), the mass increases progressively up to a maximum $\left(\Delta m_{1}\right)$ during the exposure phase (S1). Then a mass loss is measured during the purging phase (S2). A similar trend is observed after the $\mathrm{O}_{3}$ pulse: a mass increase $\left(\Delta m_{2}\right)$ is measured during the exposure time (S3) followed by a total mass loss during the purging phase (S4).

It is difficult to correlate the mass gain and loss measured by the QCM with a reaction mechanism. Thus few data can be found in literature about such chemical processes. However, Martinson et al. proposed a detailed investigation of the $\mathrm{Fe}_{2} \mathrm{O}_{3}$ formation from $\mathrm{FeCp}_{2}$ and $\mathrm{O}_{3}$ precursors by using quadrupole mass spectrometry (QMS) [35]. Since the precursors used for this deposition are close to those employed in the present study, the Martinson mechanism may be adapted to the deposition of $\mathrm{NiO}$ using $\mathrm{NiCp}_{2}$ and $\mathrm{O}_{3}$. Therefore, the $\mathrm{S} 1$ period could be ascribed to the adsorption of $\mathrm{NiCp}_{2}$ on the whole surface, which after reaction on the active sites yields a $-\mathrm{NiCp}$ group on the surface and one cyclopentadiene molecule is released. Note that Martinson et al. have also detected cyclopentadione as a byproduct in the ferrocene process. During the S2 stage, the

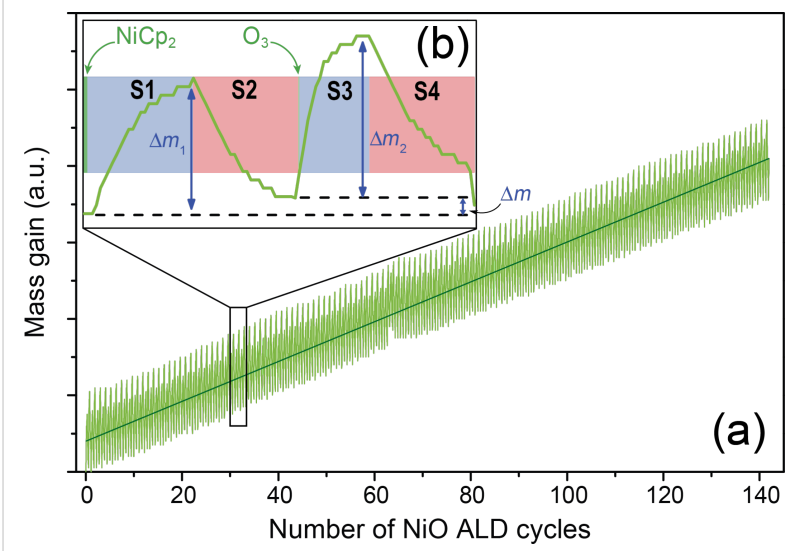

Figure 2: (a) In situ QCM measurement of the $\mathrm{NiO}$ mass gain during the ALD process. (b) Enlarged view of the mass gain for one ALD cycle. $\Delta m$ corresponds to the net mass increase after the ALD cycle.

desorption of the precursors that have not reacted with active surface sites seems to occur. The net mass gain detected after the nickelocene pulse, exposure and purging could be attributed to the bonding of a $-\mathrm{NiCp}$ group with a surface $-\mathrm{OH}$ group.

According to the study performed on $\mathrm{Fe}_{2} \mathrm{O}_{3}$ [35], the $\mathrm{S} 3$ and $\mathrm{S} 4$ stages could be associated to a combustion of the chemisorbed -NiCp groups. Those cyclopentadienyl groups should therefore be cracked with the production of $\mathrm{CO}_{2}$ and $\mathrm{H}_{2} \mathrm{O}$. The surface is then activated again with hydroxyl functions onto the $\mathrm{Ni}$ atoms. While a mass loss, corresponding to the combustion of $\mathrm{Cp}$, is expected after the $\mathrm{O}_{3}$ exposure, the QCM measurements (Figure 2b) do not show any net mass decrease during the step. 
This unexpected measurement could be attributed to a cooling effect of the vector gas (Ar) on the quartz. The QCM is indeed a very sensitive characterization tool as the sensor oscillation frequency can easily change when low temperature variations occur. Additional experiments have thus been performed by pulsing only ozone. Without $\mathrm{NiCp}_{2}$, the QCM data exhibit a low level background and no regular increase. This indicates that the general trends of $m$ vs $t$ shown in Figure 2a are relevant but no mechanistic information can be deduced from the detailed interpretation of the QCM measurements. QMS investigation would be required to support the proposed chemical mechanism.

In order to characterize their morphology, the resulting $\mathrm{NiO} / \mathrm{Ni}$ layers have been studied by electron microscopy. The backscattering electron detection mode was used to enhance the chemical contrast of the image shown in Figure 3. The NiO deposit (red color in the figure) is clearly visible within the $\mathrm{Al}_{2} \mathrm{O}_{3}$ pores. The NiO film is approximately $10 \mathrm{~nm}$ thick after 1000 ALD cycles. The TEM picture presented in Figure 4 shows the as-grown $\mathrm{NiO}$ layer deposited within the AAO membrane after removal of the alumina template. The average length of the nanotubes is $5 \mu \mathrm{m}$, which indicates that the exposure time to $\mathrm{NiCp}_{2}$ is sufficiently long to allow for the deposition to proceed deeply on the entire surface of the pores. On such a TEM image, several $\mathrm{NiO}$ nanotubes can be observed. The $\mathrm{NiO}$ layer covers the AAO template homogeneously. Note that no gradient of NiO loading is observed in the deep section of the template. The quantity of matter is identical at the top and the at the bottom of the pores. This is attributed to the self-limiting process of the ALD. The tuning of the duration of the surface exposition to the precursors allows for the reaction of the molecules with the activated surface of the three-dimensional substrates, which exhibit a high aspect-ratio geometry.

The TEM image shows that the morphology of the NiO deposit is highly granular. It therefore increases the active surface area of the electrode for a higher interaction with the electrolyte. Note that the NiO layer is an efficient barrier between the solution and the AAO since we have never observed the dissolution of the AAO during the electrochemical characterizations. To get a metallic Ni film, the as-grown $\mathrm{NiO}$ deposit has been annealed in $\mathrm{H}_{2}$ atmosphere at $300{ }^{\circ} \mathrm{C}$. The SEM observations indicate no significant morphological modifications of the Ni after the reductive annealing (Figure 5). The NiO film shown in Figure 3 (before annealing) exhibits a granularity slightly higher than in Figure 5 (after annealing). It is however difficult to get quantitative results from such SEM pictures. Note that inversely, a treatment performed in $\mathrm{Ar}$ at higher temperature $\left(T=700{ }^{\circ} \mathrm{C}\right)$ has shown a strong increase of the granularity after such annealing [34].

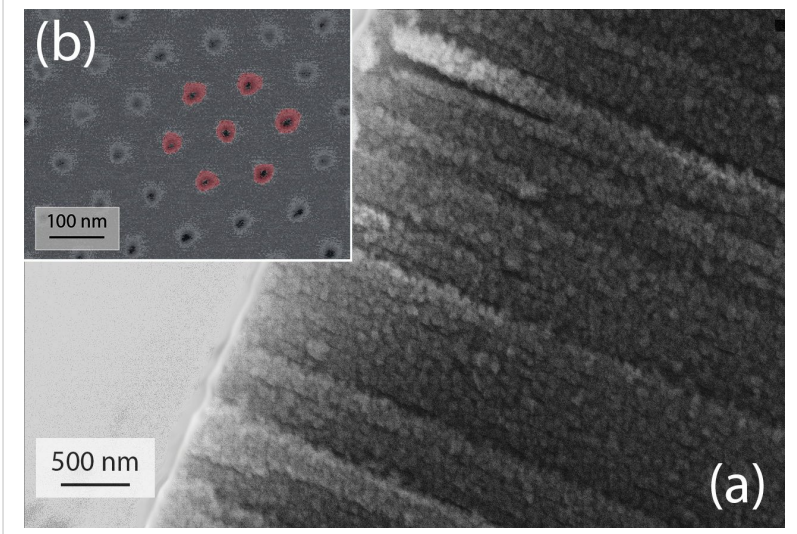

Figure 3: (a) SEM cross section of a NiO layer deposited in AAO membrane. (b) SEM image (obtained in backscattering electron mode) showing $\mathrm{NiO}$ grown by ALD within the AAO template. The NiO top layer has been removed by a short Ar sputtering in order to reveal the $\mathrm{NiO}$ film coating the vertical pore walls. The NiO deposit is emphasized on the picture using a red overlay.

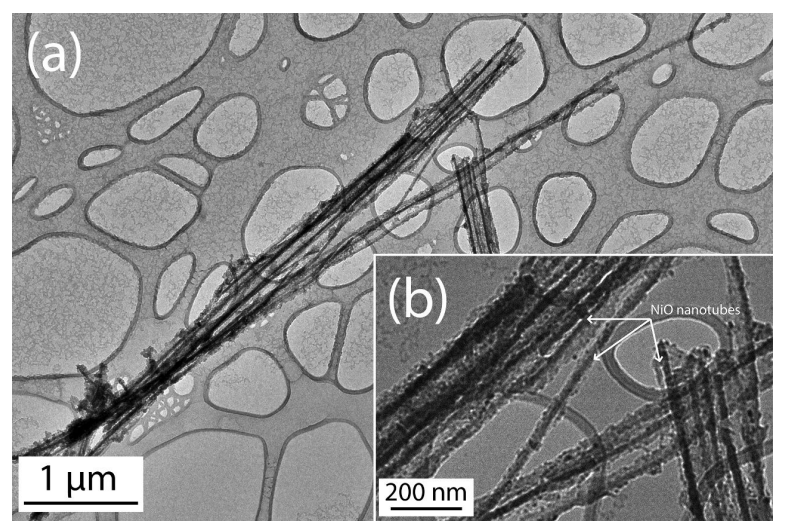

Figure 4: (a) TEM image of $\mathrm{NiO}$ nanotubes after alumina template removal. (b) Enlarged view of $\mathrm{NiO}$ nanotubes.

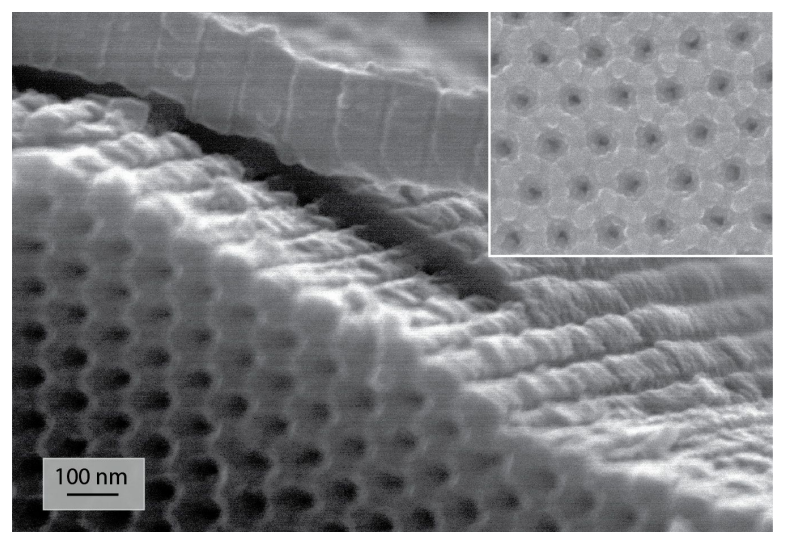

Figure 5: SEM image of Ni layer deposited in an AAO template after $3 \mathrm{~h}$ annealing in $\mathrm{H}_{2}$ at $300{ }^{\circ} \mathrm{C}$ of the initially deposited NiO by ALD.

The inset shows a detailed top-view of the surface. 
The chemical composition as well as the crystal structure of the $\mathrm{NiO} / \mathrm{Ni}$ layer have been analyzed before and after the reduction stage. The XRD analyses performed on as-grown $\mathrm{NiO}$ and after the reduction process indicate that both $\mathrm{NiO}$ and $\mathrm{Ni}$ layers deposited on AAO are amorphous (XRD patterns are shown in Figure S1, Supporting Information File 1). The surface chemistry of the sample after the reductive annealing of the $\mathrm{Ni}$ deposit has been analyzed by XPS. As expected, the spectrum shown in Figure 6 exhibits peaks corresponding to $\mathrm{Ni}, \mathrm{C}$ and $\mathrm{Si}$ but also to O. Although the Ni 2p, Ni 3p and Auger peaks indicate the presence of metallic $\mathrm{Ni}$, the $\mathrm{O}$ 1s peak suggests that the $\mathrm{Ni}$ deposit remains partially oxidized after the reductive treatment. Since the XPS analysis provides information on the outermost surface, the $\mathrm{Ni}-\mathrm{O}$ contribution can either originate from an only partial reduction of the initial $\mathrm{NiO}$ layer or from the oxidation of the sample while transferring it to the XPS chamber. Note that a contribution coming from $\mathrm{SiO}_{2}$ in the XPS spectrum in the $\mathrm{O} 1 \mathrm{~s}$ binding energies region is possible since an interfacial $\mathrm{SiO}_{2}$ layer is formed between $\mathrm{Si}$ and $\mathrm{NiO}$ (Figure $\mathrm{S} 2$,

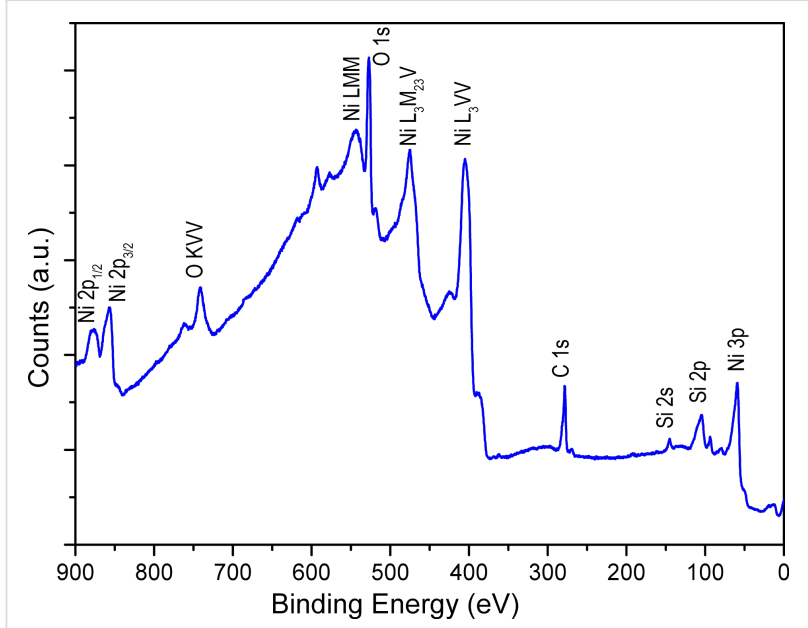

Figure 6: XPS survey spectrum of metallic Ni.
Supporting Information File 1). However, the contribution of Si in the survey spectrum is not intense.

\section{Palladium deposition}

A key advantage of ALD is that the growth of materials proceeds according to a two-dimensional mechanism. Nevertheless, for electrocatalytic applications, it is more suitable to have metallic clusters. To obtain such a morphology, it is possible to adjust the deposition parameters and the nature of the precursor. The outcome will depend also on the interaction between the substrate and the deposit. Recently, Elam et al. [25] have reported the synthesis of sub-nanometer Pd particles by an alternating exposure of the substrate to the metallic precursor and to trimethylaluminum. The active hydroxyl sites are thus occupied, which hinders the lateral growth of the particles. As mentioned in the introduction, the growth of Pd clusters by a direct ALD process, which uses palladium hexafluoroacetylacetone $\left(\mathrm{Pd}(\mathrm{hfac})_{2}\right)$ and formaldehyde, has been previously described [25,36-38]. The mechanism is summarized in Figure 7. Steps 1 and 2 consist of the adsorption of the $\mathrm{Pd}(\mathrm{hfac})_{2}$ precursor onto the surface and its reaction with the hydroxyl sites and a subsequent $\mathrm{H}$-hfac release. After the exposition of the surface to the second precursor (step 3), $\mathrm{Pd}(\mathrm{hfac}$ ) is reduced by formaldehyde. A $-\mathrm{Pd}-\mathrm{H}_{\mathrm{x}}$ termination is created at the active site and $\mathrm{Hhfac}, \mathrm{CO}$ and $\mathrm{H}_{2}$ are released during step 4.

The formation process of the Pd clusters has been monitored by QCM measurements in order to detect the mass gain and loss during the ALD cycles. The general evolution of $m$ during the deposition is shown in Figure 8a. Two growth regimes are identified in the curve: before and after 50 cycles. At first, the growth rate of $\mathrm{Pd}$ is low and non-linear. It progressively increases and reaches an almost linear growth after 50 ALD cycles. Such behavior has already been observed [36,39]. The initial low growth rate has been attributed to the long nucleation stage of the Pd clusters onto oxidized surfaces and/or

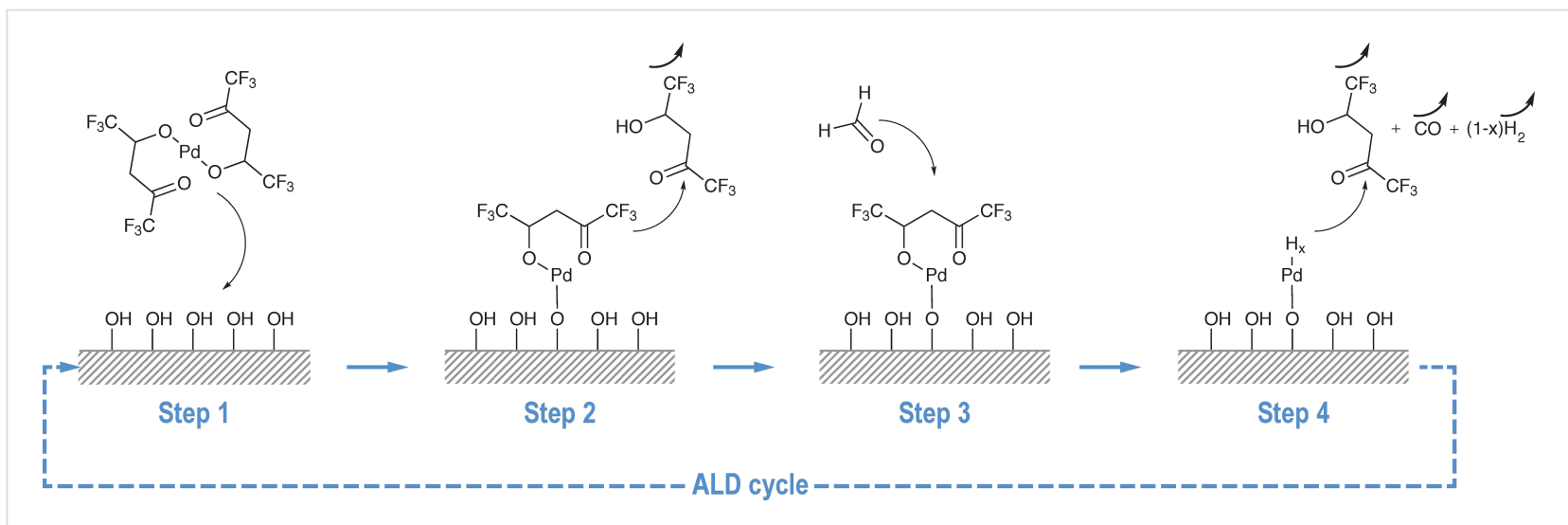

Figure 7: ALD sequence during $\mathrm{Pd}$ deposition from $\mathrm{Pd}(\mathrm{hfac})_{2}$ and formaldehyde. 


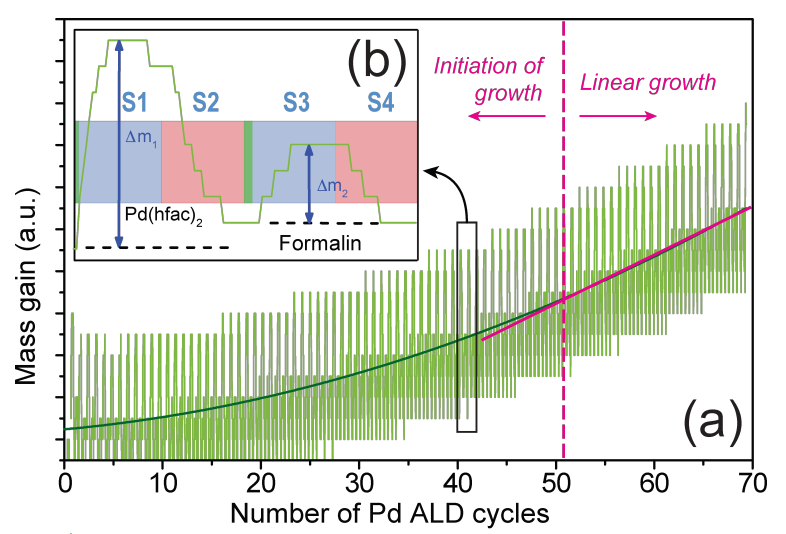

Figure 8: In situ QCM measurements of Pd mass gain during the ALD process for Pd. (a) General evolution and (b) enlarged view of one ALD cycle.

ascribed to the surface poisoning by the precursor ligands by others [38]. An enlarged view on one ALD cycle (Figure 8b) shows the details of the mass gain and loss during the precursor pulses and the pumping of the exposition chamber. Step S1 consists of the adsorption of $\mathrm{Pd}(\mathrm{hfac})_{2}$ precursor molecules onto the surface. At this stage, the mass gain is denoted $\Delta m_{1}$. The end of the exposure time (S1) does not correspond exactly to the maximum of the gain mass $\Delta m_{1}$. The exposure time could thus be decreased to optimize the cycle duration. However, a long exposure duration assures the diffusion of the chemical species toward the pore tips. A similar observation can be done for the pumping time (step S2). Its duration is also not optimized but a longer purge and pumping stage would surely remove all the byproducts and the excess of reactants. George et al. [38] have shown that during the exposure with $\mathrm{Pd}(\mathrm{hfac})_{2}$, the released Hhfac can adsorb onto the hydroxylated Ni surface and block any further Pd reaction at those locations. As mentioned above, this phenomenon can hinder the lateral growth of the Pd film and slows down the deposition rate at the beginning. Steps S3 and S4 describe the surface exposure to the second precursor (formaldehyde) and the purge/pumping of the reactor, respectively. At the end of second part of the ALD cycle, the net mass variation should be negative. After the reaction of $\mathrm{HCOH}$ with $-\mathrm{Ni}-\mathrm{O}-\mathrm{Pd}(\mathrm{hfac}), \mathrm{H}-\mathrm{hfac}, \mathrm{CO}$ and $\mathrm{H}_{2}$ are indeed released. However, the QCM measurements show no mass loss. This unexpected measurement could again be attributed to the cooling effect of the vector gas on the quartz oscillation that has been mentioned above for Ni deposition. These data give only an indication on the general deposition process and cannot be used to interpret the growth mechanism. QCM data indicate that Pd deposition takes place onto the surface since the general trend is almost flat if no Pd is pulsed in the chamber.

The morphologies of the Pd films grown onto the NiO layer have been observed by SEM and AFM with and without the reductive annealing treatment in $\mathrm{H}_{2}$. In order to facilitate such characterizations, the observed $\mathrm{NiO}$ and $\mathrm{Pd}$ layers have been grown onto flat Si substrates. Note that these depositions onto planar Si and onto AAO membranes have been performed simultaneously. Pd deposits carried out onto as-grown and annealed $\mathrm{NiO}$ layers that were grown before onto the $\mathrm{Si}$ wafers are presented in Figure 9a and Figure 9b, respectively. Their average diameters are, respectively, about 40 and 10-20 nm. The size of the clusters observed in Figure 9a cannot be attributed to the supporting $\mathrm{NiO}$ crystallites since their average size is in the range of $10-15 \mathrm{~nm}$ according to TEM cross section shown as supplemental material (Figure S2, Supporting Information File 1). The QCM, XPS and XRD measurements also attest the deposition of Pd onto the NiO layers. Such a spher-
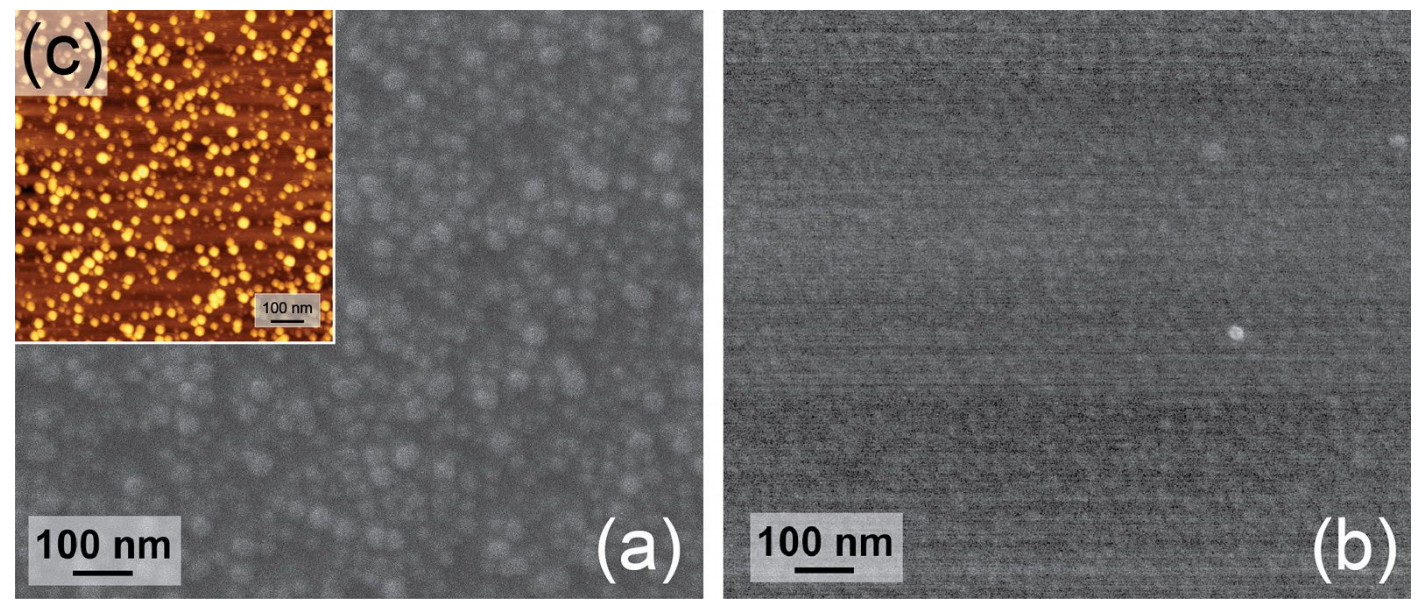

Figure 9: SEM top views of Pd deposits after 100 ALD cycles onto (a) as-grown NiO and (b) reduced NiO films on Si substrate. (c) AFM image of Pd clusters onto as-grown ALD NiO. 
ical morphology suggests a Volmer-Weber growth mechanism of Pd. Such a formation of 3D islands is due to the high difference of surface energies between the metallic $\mathrm{Pd}$ and the oxidized support $[39,40]$. The formation of $3 \mathrm{D}$ islands can also be supported by the H-hfac ligands that are adsorbed on active $-\mathrm{OH}$ sites at the surface after the $\mathrm{Pd}(\mathrm{hfac})_{2}$ pulse [38]. In the case of Figure 9b, it was more difficult to observe the clusters with a high resolution. However the average size is slightly higher than the initial $\mathrm{Ni} / \mathrm{NiO}$ layer. It indicates therefore that the $\mathrm{Pd}$ deposit covers the $\mathrm{Ni} / \mathrm{NiO}$ film uniformly. This could be due to a lower surface energy between the Pd and the annealed substrate. It is even possible to form a $\mathrm{Pd} / \mathrm{Ni}$ alloy if the $\mathrm{NiO}$ top layer appears only when the sample is exposed to air.

The two different growth mechanisms demonstrate the strong influence of the substrate on the deposition process. Although the XPS data indicate that the reduction of $\mathrm{NiO}$ to $\mathrm{Ni}$ is not total, the Pd deposition proceeds according to a $2 \mathrm{D}$ growth mechanism after the annealing in $\mathrm{H}_{2}$ atmosphere. In order to optimize the catalyst morphology, it appears that the Pd deposition should be performed onto as-grown NiO because bigger Pd islands are formed then. The AFM image presented in Figure 9c, shows clearly the Pd clusters that cover all of the Ni/ NiO layer surface. Since Figure 9a and Figure 9b show planar substrates, they cannot be used to precisely evaluate the size of the Pd particles in the NiO/AAO system. However they give valuable information about the nucleation process of the Pd clusters on the $\mathrm{NiO}$ and $\mathrm{Ni}$ surfaces. Since atomic layer deposition is a self-limiting layer-by-layer process, it is reasonable to assume that the deposition occurs within the AAO/NiO structures but the particle size should be lower than the one observed on planar substrate. The crystal structure of Pd deposit has been investigated by X-ray diffraction. The XRD patterns shown in Figure 10 depict a polycrystalline structure of the Pd layer with a preferential orientation in the [220] direction (peak at about $70^{\circ}$ ). The $\mathrm{Pd}$ crystallographic structure is face centred cubic (fcc) similar to the structure of bulk Pd metal [11]. The XRD diffractogram suggests therefore the presence of metallic Pd. This result is further confirmed by the XPS analysis (Figure 11) that has revealed the presence of $\mathrm{Pd}, \mathrm{O}$ and $\mathrm{C}$ on the surface. Similarly to $\mathrm{Ni}$, the spectrum indicates the contribution of metallic and oxidized $\mathrm{Pd}$ with a slight contribution of $\mathrm{O}$. The presence of $\mathrm{Pd}-\mathrm{O}$ bonds can also be attributed to the oxidation occurring during the sample transfer to the XPS chamber or to the Pd deposition process itself. As observed for $\mathrm{Ni}$, the $\mathrm{Pd}$ layer contains a small amount of $\mathrm{C}$.

\section{Electrooxidation of $\mathrm{HCOOH}$ on $\mathrm{Pd} / \mathrm{Ni}$ layers}

According to literature [10-13], $\mathrm{Pd} / \mathrm{Ni}$ seems to be a more interesting system for the electrooxidation of $\mathrm{HCOOH}$ than $\mathrm{Pd} /$ $\mathrm{NiO}$. The electrochemical characterizations have thus been

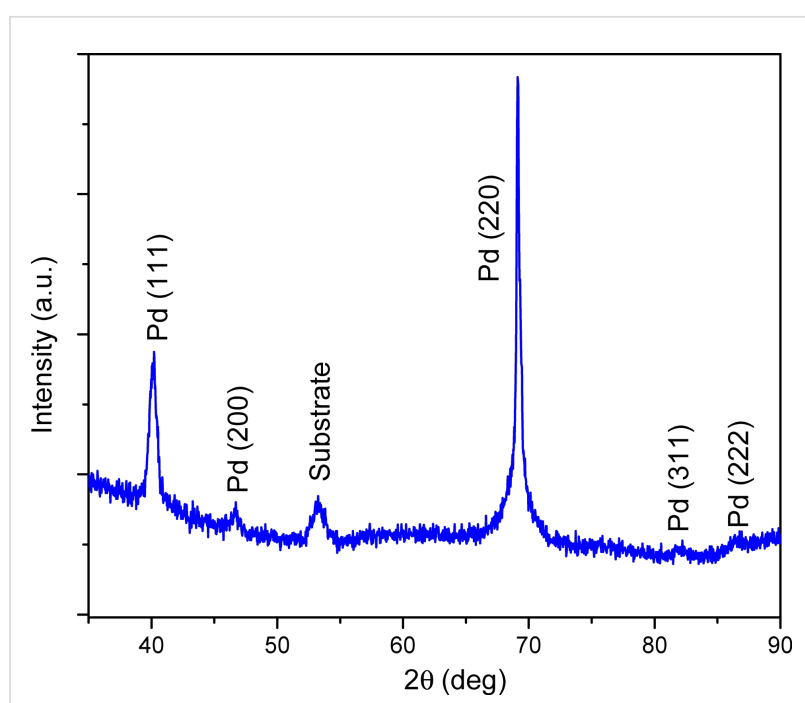

Figure 10: X-ray diffractogram of Pd deposited by ALD exhibiting a polycrystalline structure with a preferential orientation along the fcc [220] direction.

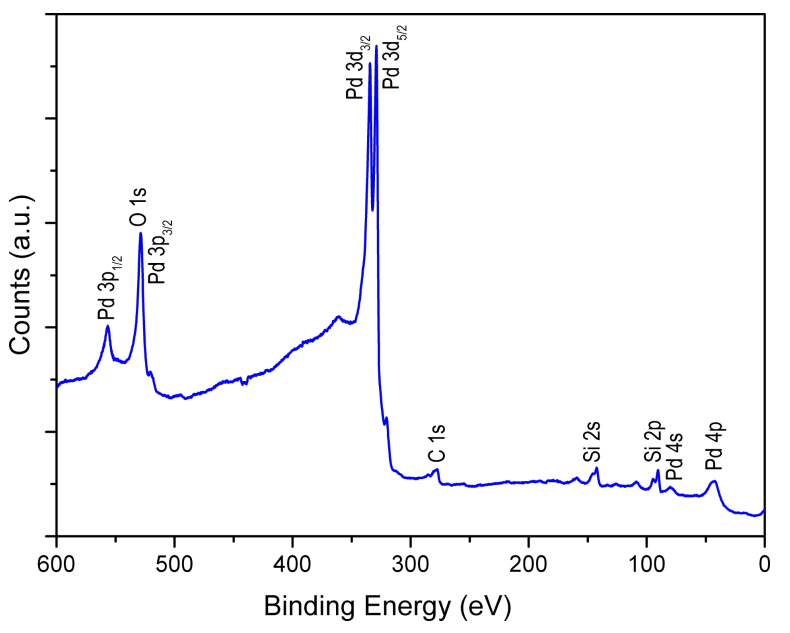

Figure 11: XPS survey spectrum of metallic Pd.

performed with the $\mathrm{H}_{2}$-annealed $\mathrm{NiO}$ layers after the deposition of Pd. Figure 12 shows the forward and reverse scans of the third $\mathrm{CV}$ cycle on $\mathrm{Pd} / \mathrm{Ni}$ electrocatalysts deposited onto an AAO membrane in $0.5 \mathrm{M} \mathrm{H}_{2} \mathrm{SO}_{4}$ before and after adding $1 \mathrm{M}$ $\mathrm{HCOOH}$. From cycle number 1 until cycle number 3, a decrease of the electrocatalytic activity of $\mathrm{Pd} / \mathrm{Ni}$ system is observed. Indeed, the stability of $\mathrm{Ni}$ in $\mathrm{H}_{2} \mathrm{SO}_{4}$ is not as good as in $\mathrm{KOH}$, however in the potential region of interest no $\mathrm{Pd} / \mathrm{Ni}$ deactivation due to Ni dissolution has been observed. The third cycle is shown because after three cycles a stable and reproducible behavior of $\mathrm{Pd} / \mathrm{Ni}$ system was obtained (CVs are identical) in the presence and absence of formic acid. The cyclic voltammogram disclosed in Figure S3 (Supporting Information File 1) 


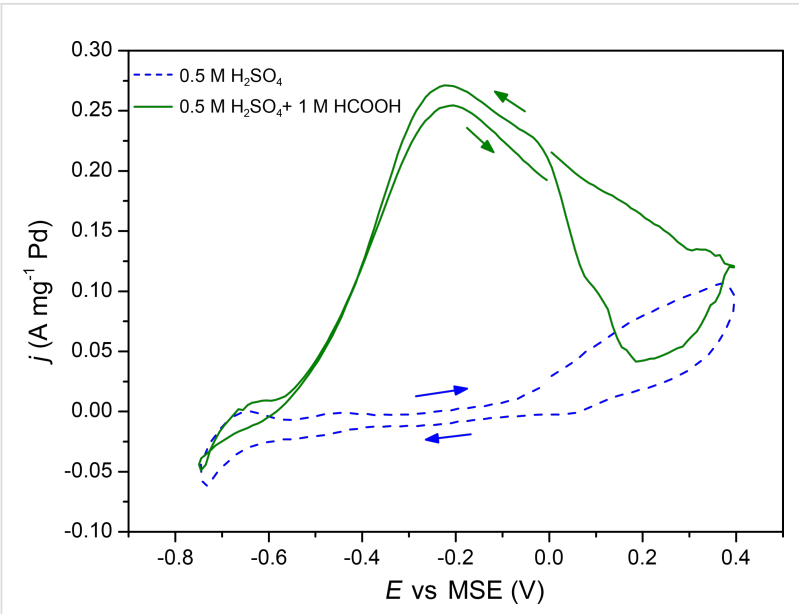

Figure 12: Cyclic voltammograms of $\mathrm{Pd}(100 \mathrm{ALD}$ cycles)/Ni(1000 ALD cycles) catalysts in $0.5 \mathrm{M} \mathrm{H}_{2} \mathrm{SO}_{4}$ without (blue dashed line) and with (continuous green line) $1 \mathrm{M} \mathrm{HCOOH}$ at $15 \mathrm{mV} \cdot \mathrm{s}^{-1}$. Current densities are given per unit mass of Pd estimated from the QCM measurements.

shows the evolution of the current during the first six cycles. It demonstrates the stability of the $\mathrm{Pd} / \mathrm{Ni}$ system over time in $0.5 \mathrm{M} \mathrm{H}_{2} \mathrm{SO}_{4}$.

The Ni and Pd layers were formed after 1000 and 100 ALD cycles, respectively, on alumina membranes. The applied potential varies from -0.75 to $0.4 \mathrm{~V}$ vs MSE at $15 \mathrm{mV} \cdot \mathrm{s}^{-1}$. At potentials lower than $-0.6 \mathrm{~V}$, the $\mathrm{H}_{2}$ adsorption/desorption process is observed. Without formic acid in the solution, at potentials between -0.6 and $0 \mathrm{~V}$, the voltammogram exhibits a flat region till approximately $0 \mathrm{~V}$ and at higher potentials the formation of Pd oxides starts to take place. In the presence of formic acid, on the other hand, the current begins to increase at a potential of $-0.58 \mathrm{~V}$ reaching a maximum current density of $0.26 \mathrm{~A} \cdot \mathrm{mg}^{-1}$ at $-0.2 \mathrm{~V}$ because of the oxidation of $\mathrm{HCOOH}$. A further increase of the potential leads to a decrease of the current density due to the oxidation of the palladium and the inhibition of the catalytic activity of the metallic system by reaction intermediates $[9,41]$. On the reverse scan, the current remains low until $0.19 \mathrm{~V}$, at which the reduction of $\mathrm{PdO}_{x}$ begins to take place, and then increases because of the electrooxidation of formic acid on the reduced Pd. Note that the anodic wave that is centered at $-0.19 \mathrm{~V}$ in the reverse scan is slightly higher than the one during the forward scan. This hysteresis indicates that the Pd surface still remains active and the previously formed oxides are completely reduced when the potential is reversed toward the negative direction. The electrooxidation of $\mathrm{HCOOH}$ follows the direct dehydrogenation pathway, which is in agreement with previous works [42]. The effect of the number of Pd ALD cycles $(40,80,100$ and 145$)$ and, consequently, the $\mathrm{Pd}$ to $\mathrm{Ni}$ ratio on the current peak at $-0.19 \mathrm{~V}$, which corresponds to the oxidation of $\mathrm{HCOOH}$ is shown in Figure 13. Additionally, the electrochemical characterizations have shown the typical $\mathrm{Pd}$ response in $\mathrm{H}_{2} \mathrm{SO}_{4}$. The obtained results (overpotential for the oxidation of formic acid) are in a good agreement with the literature data reported for $\mathrm{Pd} /$ transition metal systems prepared by other techniques $[10,13]$.

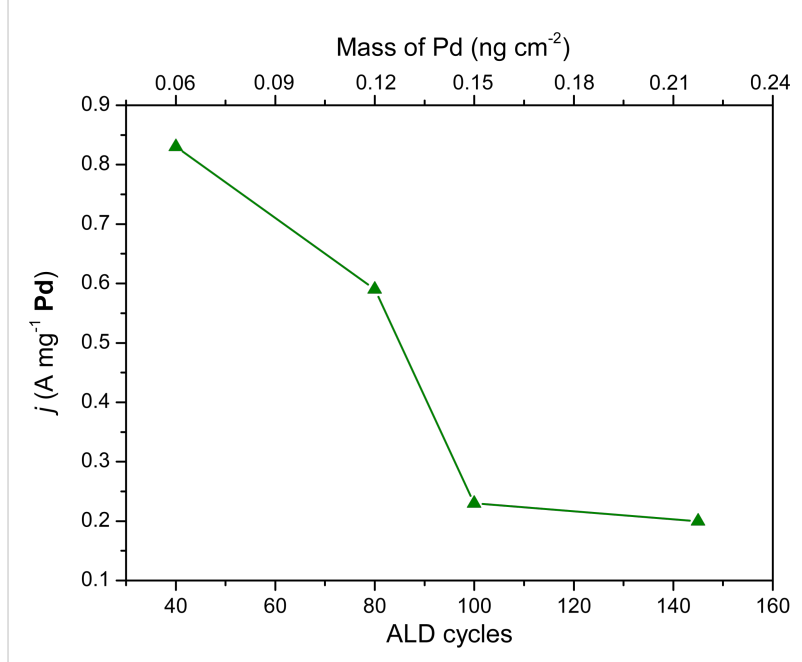

Figure 13: Peak current densities of the electrooxidation of $1 \mathrm{M}$ $\mathrm{HCOOH}$ in $0.5 \mathrm{M} \mathrm{H}_{2} \mathrm{SO}_{4}$ with various $\mathrm{Pd}$ contents in the $\mathrm{Pd} / \mathrm{Ni}$ nanocatalysts, which were obtained with 40 to 145 Pd ALD cycles. The mass of Pd was estimated from the QCM measurements.

The mass activity of the Pd systems decreases to about one fourth from 40 to 145 ALD cycles. The increase of mass of Pd may result in the formation of larger clusters, and subsequently in both a smaller overall active surface area of the catalyst per unit mass, and weaker interactions with the Ni support. These two reasons can explain the negative trend of peak current densities for the oxidation of formic acid on $\mathrm{Pd} / \mathrm{Ni}$ electrocatalysts with the increase of Pd mass. Note that it can also be because of the mass transport effect [43] since diffusion into such narrow channels can differ strongly from standard 2D models.

\section{Conclusion}

In this study, well-defined $\mathrm{Pd} / \mathrm{Ni}$ nanocatalysts grown by ALD have been investigated for the electrooxidation of formic acid in $0.5 \mathrm{M} \mathrm{H}_{2} \mathrm{SO}_{4}$. The deposition of nickel oxide from $\mathrm{NiCp}_{2}$ and $\mathrm{O}_{3}$ precursors on high aspect ratio nanoporous $\mathrm{Al}_{2} \mathrm{O}_{3}$ has been demonstrated. Although the chemical composition analysis of the NiO layers has not shown that the reductive treatment in $\mathrm{H}_{2}$ leads to fully metallic films, in which no strong morphological modifications were observed. Furthermore, it was concluded that the oxidized $\mathrm{Ni}$ is a better substrate to obtain a three-dimensional growth of $\mathrm{Pd}$ islands, which are more suitable for electrocatalytic applications. The Pd deposit is polycrystalline and exhibits a preferential orientation along the [220] direction. For 
both Ni and Pd depositions, the QCM results were not conclusive with regard to proper information about the deposition mechanisms by ALD. The Pd/Ni bimetallic systems demonstrates a high activity toward the electrooxidation reaction of formic acid and reaches $0.83 \mathrm{~A} \cdot \mathrm{mg}^{-1}$ for Pd(40 ALD cycles)/ $\mathrm{Ni}(1000$ ALD cycles). The electrochemical properties are very similar to those reported in the literature [10-13]. The interaction between $\mathrm{Pd}$ and $\mathrm{Ni}$ is stronger when the mass of the deposited Pd is decreased because of the lower thickness and size of Pd particles, but also because of the electronic effects between the alloyed $\mathrm{Pd} / \mathrm{Ni}$ metals or because of the mass transport effect in 3D nanostructures. This explains the trend of higher peak current densities for the electrooxidation of formic acid at a lower $\mathrm{Pd}$ content in the $\mathrm{Pd} / \mathrm{Ni}$ nanocatalysts.

\section{Experimental}

The porous alumina structures have been grown on $4 \mathrm{~cm}$ wide aluminum discs (Goodfellow, 99.999\%) by using the method that is schematically depicted in Figure 1a-e. The aluminum was first electropolished in an alcoholic solution of perchloric acid and successively anodized at a constant voltage, $U$, of $40 \mathrm{~V}$ in oxalic acid. A chemical dissolution was performed between the two anodizations to remove the disordered sacrificial $\mathrm{Al}_{2} \mathrm{O}_{3}$ layer. The resulting alumina membrane is ordered on a large scale area (ca. $10 \mathrm{~cm}^{2}$ ); the pore diameter is $40 \mathrm{~nm}$ and the length of the pores is about $5 \mu \mathrm{m}$. A typical AAO template is shown in Figure 14.

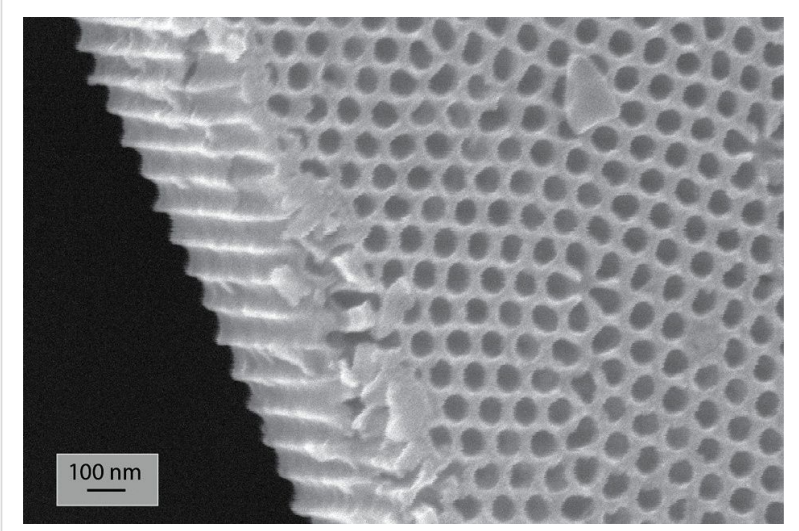

Figure 14: SEM micrograph of an anodic alumina oxide template. After the electropolishing, a sacrificial film was firstly grown by applying $40 \mathrm{~V}$ in $0.3 \mathrm{M} \mathrm{H}_{2} \mathrm{C}_{2} \mathrm{O}_{4}$ for $24 \mathrm{~h}$ at $T=8^{\circ} \mathrm{C}$ and then dissolved in $\mathrm{H}_{2} \mathrm{CrO}_{4}$ and $\mathrm{H}_{3} \mathrm{PO}_{4}$ at $50{ }^{\circ} \mathrm{C}$ for $12 \mathrm{~h}$. The second anodization step is then carried out during $2.5 \mathrm{~h}$ at the same anodic conditions.

The $\mathrm{Pd} / \mathrm{Ni}$ catalysts have been prepared by ALD in a Fiji 200 reactor from Ultratech/Cambridge Nanotech. The catalysts $(\mathrm{Ni}$ and $\mathrm{Pd}$ ) were deposited both on AAO membranes and on flat $\mathrm{Si}(100)$ wafers that were cleaned beforehand by sonication in acetone, isopropanol and ethanol and deoxidized by dipping in
$1 \% \mathrm{HF}$ for $5 \mathrm{~s}$. The alumina template was coated by a thin $\mathrm{NiO}$ layer grown from nickelocene $\left(\mathrm{NiCp}_{2}, 99 \%\right.$ from STREM chemicals), and ozone as chemical precursors. The temperature of the ALD chamber during the deposition was set to $250{ }^{\circ} \mathrm{C}$. The ALD cycle consisted of successive exposures of the sample to $\mathrm{NiCp}_{2}$ and $\mathrm{O}_{3}$. The pulse durations and exposure time were, respectively, 1 and $30 \mathrm{~s}$ for $\mathrm{NiCp}_{2}$ and 0.2 and $20 \mathrm{~s}$ for $\mathrm{O}_{3}$. In both cases, the purging of the chamber was carried out for $30 \mathrm{~s}$. The resulting $\mathrm{NiO}$ film was annealed and reduced under a $\mathrm{H}_{2}$ flow at $300{ }^{\circ} \mathrm{C}$ for $3 \mathrm{~h}$ to obtain a metallic Ni layer. The last step of the preparation of the catalysts consisted of depositing Pd nanoclusters that have been grown from palladium(II) hexafluoroacetylacetonate $\left(\operatorname{Pd}(\mathrm{hfac})_{2}, 98 \%\right.$ from STREM chemicals), and formalin (37\% formaldehyde in water with $10-15 \%$ of methanol from Sigma-Aldrich) at $200{ }^{\circ} \mathrm{C}$. The ALD sequence consisted of successive exposures of the Ni-covered sample to $\mathrm{Pd}(\mathrm{hfac})_{2}$ and formaldehyde. The pulse durations were, respectively, 1 and $3 \mathrm{~s}$. In both cases, the exposure and purge durations were $30 \mathrm{~s}$. Due to the low vapor pressure of the Pd precursor, an argon flow has been injected in the canister for $0.25 \mathrm{~s}$ through an additional valve before each precursor pulse in order to enhance the transport of chemical species toward the deposition chamber. Experiments with various number of ALD cycles of the different precursors have been performed to adjust the mass and the composition of the films. A chemical etching performed in chromic acid solution allows to chemically dissolve the alumina template to allow for the nanostructured catalysts to be collected by centrifugation for further TEM observations of the catalysts out of the alumina template. The $\mathrm{Pd} / \mathrm{Ni}$ catalysts have been deposited both on 3D alumina templates and flat $\mathrm{Si}(100)$ wafers in order to facilitate the chemical and structural characterizations. In situ monitoring of the relative mass gain and loss was performed by using a quartz crystal microbalance (QCM from Inficon). The QCM is connected to the ALD chamber and driven by a SQM-160 controller for data acquisition. The morphology of $\mathrm{Al}_{2} \mathrm{O}_{3}$ templates and $\mathrm{Pd} / \mathrm{Ni}$ electrocatalysts has been observed by SEM and TEM using, respectively, JEOL 6320-F and JEOL 3010 equipment. Some additional morphological investigations have been carried out by non-contact AFM using a XE 100 microscope from Park systems. The crystalline structure of $\mathrm{NiO}, \mathrm{Ni}$ and $\mathrm{Pd}$ has been characterized by X-ray diffraction using an INEL diffractometer equipped with a quartz monochromator and a horizontally disposed 1D curved position detector (CPS120) that covers a $2 \theta$ angle of $120^{\circ}$. The measurements were obtained in reflection mode with an incident angle of $10^{\circ}$ and $\mathrm{Cu} \mathrm{K \alpha 1}(1.54056 \AA$ ) radiation. X-ray photoelectron spectroscopy by using a $\mathrm{Mg}$ electrode $\mathrm{K} \alpha(1253.6 \mathrm{eV})$ source (HA150 from VSW) was used for surface chemistry composition analysis. The Electrooxidation of $\mathrm{HCOOH}$ on aluminasupported $\mathrm{Pd} / \mathrm{Ni}$ catalysts after reductive annealing treatment of 
the $\mathrm{NiO}$ ALD layer has been studied in $0.5 \mathrm{M} \mathrm{H}_{2} \mathrm{SO}_{4}$ solution in a three-electrode teflon cell. A large surface area Pt mesh and a mercury sulfate electrode (MSE) served respectively as counter and reference electrodes. The geometric area of the working electrode was $0.196 \mathrm{~cm}^{2}$. The electrical contact to the working electrode was established by a gold wire on the $\mathrm{Pd} / \mathrm{Ni}$ layer. Cyclic voltammetry was carried out by using a BioLogic VSP potentiostat together with the EC-Lab software at room temperature. The CVs were performed in the potential region from -0.75 to $0.4 \mathrm{~V}$ vs MSE at a scanning rate of $15 \mathrm{mV} \cdot \mathrm{s}^{-1}$. The current densities have been reported per unit mass of Pd (details on the Pd mass calculations can be found in Supporting Information File 1).

\section{Supporting Information}

\section{Supporting Information File 1}

Additional experimental details

[http://www.beilstein-journals.org/bjnano/content/

supplementary/2190-4286-5-16-S1.pdf]

\section{Acknowledgements}

The authors acknowledge Damien Chaudanson and Serge Nitsche for their precious help with the electron microscopy, Jean-Yves Hoarau for XPS analysis and Vasile Heresanu for XRD measurements and interpretation. This work was supported by the France Canada Research Fund. The European Regional Development Fund (ERDF), the PACA Regional Council, the French Ministry of Higher Education and Research and the CNRS are also acknowledged for funding.

\section{References}

1. Yu, X.; Pickup, P. G. J. Power Sources 2008, 182, 124-132. doi:10.1016/j.jpowsour.2008.03.075

2. Rice, C.; Ha, S.; Masel, R. I.; Wieckowski, A. J. Power Sources 2003, 115, 229-235. doi:10.1016/S0378-7753(03)00026-0

3. Rice, C.; Ha, S.; Masel, R. I.; Waszczuk, P.; Wieckowski, A.; Barnard, T. J. Power Sources 2002, 111, 83-89. doi:10.1016/S0378-7753(02)00271-9

4. Liu, Z.; Hong, L.; Tham, M. P.; Lim, T. H.; Jiang, H. J. Power Sources 2006, 161, 831-835. doi:10.1016/j.jpowsour.2006.05.052

5. Choi, J. H.; Noh, S. Y.; Han, S. D.; Yoon, S. K.; Lee, C.-S.; Hwang, T.-S.; Rhee, Y. W. Korean J. Chem. Eng. 2008, 25 , 1026-1030. doi:10.1007/s11814-008-0167-2

6. Antolini, E. Energy Environ. Sci. 2009, 2, 915-931. doi:10.1039/B820837A

7. Baik, S. M.; Han, J.; Kim, J.; Kwon, Y. Int. J. Hydrogen Energy 2011, 36, 14719-14724. doi:10.1016/j.ijhydene.2011.04.181

8. Yang, L.; Su, H.; Shu, T.; Liao, S. Sci. China: Chem. 2012, 55, 391-397. doi:10.1007/s11426-011-4485-6

9. Du, C.; Chen, M.; Wang, W.; Yin, G. ACS Appl. Mater. Interfaces 2011, 3, 105-109. doi:10.1021/am100803d
10. Xu, C.; Liu, Y.; Wang, J.; Geng, H.; Qiu, H. J. Power Sources 2012, 199, 124-131. doi:10.1016/j.jpowsour.2011.10.075

11. Shen, S. Y.; Zhao, T. S.; Xu, J. B.; Li, Y. S. J. Power Sources 2010, 195, 1001-1006. doi:10.1016/j.jpowsour.2009.08.079

12. Baranova, E. A.; Miles, N.; Mercier, P. H. J.; Page, Y. L.; Patarachao, B. Electrochim. Acta 2010, 55, 8182-8188. doi:10.1016/j.electacta.2009.12.090

13. Hu, S.; Ha, S.; Scudiero, L. Electrochim. Acta 2013, 105, 362-370. doi:10.1016/j.electacta.2013.05.012

14. Zhong, C.-J.; Luo, J.; Fang, B.; Wanjala, B. N.; Njoki, P. N.; Loukrakpam, R.; Yin, J. Nanotechnology 2010, 21, 062001. doi:10.1088/0957-4484/21/6/062001

15. Feng, H.; Elam, J. W.; Libera, J. A.; Setthapun, W.; Stair, P. C. Chem. Mater. 2010, 22, 3133-3142. doi:10.1021/cm100061n

16. Lu, J.; Liu, B.; Greeley, J. P.; Feng, Z.; Libera, J. A.; Lei, Y.; Bedzyk, M. J.; Stair, P. C.; Elam, J. W. Chem. Mater. 2012, 24, 2047-2055. doi:10.1021/cm300203s

17. Haukka, S.; Lakomaa, E. L.; Suntola, T. Adsorption controlled preparation of heterogeneous catalysts. In Adsorption and its Applications in Industry and Environmental Protection; Dabrowski, A., Ed.; Studies in Surface Science and Catalysis, Vol. 120A; Elsevier: Amsterdam, 1999; pp 715-750.

18. Detavernier, C.; Dendooven, J.; Sree, S. P.; Ludwig, K. F.; Martens, J. A. Chem. Soc. Rev. 2011, 40, 5242-5253. doi:10.1039/c1cs15091j

19. Elam, J. W.; Dasgupta, N. P.; Prinz, F. B. MRS Bull. 2011, 36, 899-906. doi:10.1557/mrs.2011.265

20. Lu, J.; Elam, J. W.; Stair, P. C. Acc. Chem. Res. 2013, 46, 1806-1815. doi:10.1021/ar300229c

21. Goldstein, D. N.; George, S. M. Appl. Phys. Lett. 2009, 95, 143106. doi:10.1063/1.3238558

22. Binder, A.; Seipenbusch, M. Appl. Catal., A 2011, 396, 1-7. doi:10.1016/j.apcata.2010.12.030

23. Liang, X.; Lyon, L. B.; Jiang, Y.-B.; Weimer, A. W. J. Nanopart. Res. 2012, 14, No. 943. doi:10.1007/s11051-012-0943-0

24. Rikkinen, E.; Santasalo-Aarnio, A.; Airaksinen, S.; Borghei, M.; Viitanen, V.; Sainio, J.; Kauppinen, E. I.; Kallio, T.; Krause, A. O. I. J. Phys. Chem. C 2011, 115, 23067-23073. doi:10.1021/jp2083659

25. Feng, H.; Libera, J. A.; Stair, P. C.; Miller, J. T.; Elam, J. W. ACS Catal. 2011, 1, 665-673. doi:10.1021/cs2000957

26. Chen, Y.-X.; Lavacchi, A.; Chen, S.-P.; di Benedetto, F.; Bevilacqua, M.; Bianchini, C.; Fornasiero, P.; Innocenti, M.; Marelli, M.; Oberhauser, W.; Sun, S.-G.; Vizza, F. Angew. Chem., Int. Ed. 2012, 51, 8500-8504. doi:10.1002/anie.201203589

27. Moyen, E.; Santinacci, L.; Masson, L.; Sahaf, H.; Macé, M.; Assaud, L.; Hanbücken, M. Int. J. Nanotechnol. 2012, 9, 246-259. doi:10.1504/IJNT.2012.045330

28. Moyen, E.; Santinacci, L.; Masson, L.; Wulfhekel, W.; Hanbücken, M. Adv. Mater. 2012, 24, 5094-5098. doi:10.1002/adma.201200648

29. Rüffer, D.; Huber, R.; Berberich, P.; Albert, S.; Russo-Averchi, E.; Heiss, M.; Arbiol, J.; Fontcuberta i Morral, A.; Grundler, D. Nanoscale 2012, 4, 4989-4995. doi:10.1039/c2nr31086d

30. Peck, M. A.; Langell, M. A. Chem. Mater. 2012, 24, 4483-4490. doi:10.1021/cm300739y

31. Miikkulainen, V.; Leskelä, M.; Ritala, M.; Puurunen, R. L. J. Appl. Phys. 2013, 113, 021301. doi:10.1063/1.4757907

32. Lim, B. S.; Rahtu, A.; Gordon, R. G. Nat. Mater. 2003, 2, 749-754. doi:10.1038/nmat1000

33. Chae, J.; Park, H.-S.; Kang, S.-w. Electrochem. Solid-State Lett. 2002, 5, C64-C66. doi:10.1149/1.1475199 
34. Bachmann, J.; Zolotaryov, A.; Albrecht, O.; Goetze, S.; Berger, A.; Hesse, D.; Novikov, D.; Nielsch, K. Chem. Vap. Deposition 2011, 17, 177-180. doi:10.1002/cvde.201004300

35. Martinson, A. B. F.; DeVries, M. J.; Libera, J. A.; Christensen, S. T.; Hupp, J. T.; Pellin, M. J.; Elam, J. W. J. Phys. Chem. C 2011, 115, 4333-4339. doi:10.1021/jp110203x

36. Elam, J. W.; Zinovev, A.; Han, C. Y.; Wang, H. H.; Welp, U.; Hryn, J. N.; Pellin, M. J. Thin Solid Films 2006, 515, 1664-1673. doi:10.1016/j.tsf.2006.05.049

37. Stair, P. C. J. Chem. Phys. 2008, 128, 182507. doi:10.1063/1.2824939

38. Goldstein, D. N.; George, S. M. Thin Solid Films 2011, 519, 5339-5347. doi:10.1016/j.tsf.2011.02.037

39. Weber, M. J.; Mackus, A. J. M.; Verheijen, M. A.; van der Marel, C.; Kessels, W. M. M. Chem. Mater. 2012, 24, 2973-2977. doi:10.1021/cm301206e

40. Campbell, C. T. Surf. Sci. Rep. 1997, 27, 1-111. doi:10.1016/S0167-5729(96)00011-8

41. Capon, A.; Parsons, R. J. Electroanal. Chem. 1975, 65, 285-305. doi:10.1016/0368-1874(75)85124-0

42. Li, R.; Wei, Z.; Huang, T.; Yu, A. Electrochim. Acta 2011, 56, 6860-6865. doi:10.1016/j.electacta.2011.05.097

43. Lindström, R. W.; Seidel, Y. E.; Jusys, Z.; Gustavsson, M.; Wickman, B.; Kasemo, B.; Behm, R. J. J. Electroanal. Chem. 2010, 644, 90-102. doi:10.1016/j.jelechem.2009.04.034

\section{License and Terms}

This is an Open Access article under the terms of the Creative Commons Attribution License (http://creativecommons.org/licenses/by/2.0), which permits unrestricted use, distribution, and reproduction in any medium, provided the original work is properly cited.

The license is subject to the Beilstein Journal of Nanotechnology terms and conditions: (http://www.beilstein-journals.org/bjnano)

The definitive version of this article is the electronic one which can be found at:

$\underline{\text { doi:10.3762/bjnano.5.16 }}$ 